\title{
Uso da Ultra-Sonografia no Diagnóstico e Seguimento do Carcinoma Bem Diferenciado da Tireóide
}

\begin{abstract}
RESUMO
Os nódulos tireóideos são encontrados em grande parte da população, mas somente 5 a $10 \%$ são malignos. A ultra-sonografia da tireóide, por ser um método simples, não-invasivo e apresentar boa correlação com os aspectos macroscópicos da glândula tireóide, é cada vez mais utilizada para identificar os nódulos que apresentam maior risco de malignidade. A presença de algumas características ultra-sonográficas como hipoecogenicidade, microcalcificações, contornos irregulares e vascularização central ao Doppler, aumenta o risco de malignidade da lesão. Por outro lado, nódulos que apresentam características ultra-sonográficas benignas, como hiperecogenicidade e aspecto misto semelhante a uma esponja, apresentam concordância com a citologia, com valor preditivo negativo de $96,6 \%$. É importante, pois, examinarmos e classificarmos todas as lesões nodulares para selecionarmos aquelas suspeitas para a biópsia, principalmente em uma tireóide multinodular. A ultra-sonografia também apresenta alta sensibilidade para identificar gânglios cervicais suspeitos no seguimento de pacientes com carcinoma da tireóide, mesmo quando a $\mathrm{PCl}$ é negativa e a tireoglobulina $(\mathrm{Tg})$ sérica, indetectável. É recomendável a dosagem da Tg no lavado da agulha da punção, pois esta tem-se mostrado mais sensível que a citologia no diagnóstico de metástase cervical, principalmente quando existe conteúdo líquido, e não é afetada pela presença de anticorpos anti-Tg. (Arq Bras Endocrinol Metab 2007;51/5:783-792)
\end{abstract}

Descritores: Carcinoma de tireóide; Ultra-sonografia da tireóide; Punção aspirativa por agulha fina guiada pela ultra-sonografia; Nódulo tireoidiano; Doppler colorido da tireóide

\section{ABSTRACT}

Usefulness of Ultrasound in the Diagnosis and Management of WellDifferentiated Thyroid Carcinoma.

Thyroid nodules are found in the vast majority of the population, but only 5 to $10 \%$ are malignant. Ultrasonography of the thyroid, by virtue of being a straightforward, non-invasive method presenting strong correlation with macroscopic aspects of the thyroid gland, is being increasingly used to identify nodules that present a higher risk of malignancy. The presence of certain ultrasonographic characteristics such as hypoechogenicity, microcalcifications, irregular contours and central vascularization on Doppler, increase the risk of the lesion being malignant. Conversely, nodules presenting benign ultrasonographic characteristics such as hyperechogenicity and a mixed sponge-like aspect, and a concordant cytology, have a negative predictive value of $96.6 \%$. It is, thus, important to examine all nodular lesions and to identify suspicious lesions that need biopsy, especially in multinodular glands. Ultrasonography is also highly sensitive in the identification of suspicious cervical lymph nodes during the follow-up of patients with thyroid carcinoma, even when $\mathrm{PCl}$ is negative and serum thyroglobulin $(\mathrm{Tg})$ levels are undetectable. Tg measurement in the needle wash-out content is recommended as this has proven to be more sensitive than cytology in the diagnosis of cervical metastasis, especially where there is liquid content, and it is not affected by the presence of anti-Tg antibodies. (Arq Bras Endocrinol Metab 2007;51/5:783-792)

Keywords: Thyroid carcinoma; Ultrasonography of the thyroid; Ultrasonographically guided fine needle aspirative puncture; Thyroidal nodule; Color Doppler of the thyroid

\section{revisão}

\section{ROSALINDA Y.A. DE CAMARGO EDUARDO KIYOSHI TOMIMORI}

Unidade de Tireóide da Disciplina de Endocrinologia do Hospital das Clínicas da Faculdade de Medicina da Universidade de São Paulo, SP. 
$\mathrm{O}$ S NÓDULOS DA TIREÓIDE são detectados clinicamente em cerca de $4 \%$ a $7 \%$ da população geral $(1,2)$ e essa freqüência aumenta para $30 \%$ a $50 \%$ quando a ultra-sonografia é utilizada $(3,4)$.

A ultra-sonografia da tireóide, por ser um método simples, não-invasivo e apresentar boa correlação com os aspectos macroscópicos dos nódulos tireóideos, é um procedimento cada vez mais utilizado na avaliação inicial da lesão nodular da tireóide. Atualmente, a Associação Americana de Tireóide recomenda a realização do exame ultra-sonográfico em todos os pacientes com suspeita de um ou mais nódulos tireóideos (5). Nenhum sinal ultrasonográfico é patognomônico para malignidade. A combinação de algumas características, como presença de microcalcificações, hipoecogenicidade e contornos irregulares, aumenta o risco de malignidade de uma lesão. Dessa forma, a ultra-sonografia pode identificar as lesões nodulares com maior potencial de malignidade, permitindo selecionar nódulos para biópsias em uma tireóide multinodular. Entretanto, os carcinomas bem diferenciados nem sempre apresentam características ultra-sonográficas de malignidade (6). Na prática clínica é importante identificar não só os nódulos suspeitos para malignidade como também estimar o risco de malignidade para as demais lesões nodulares da tireóide. Os nódulos tireoidianos benignos ou malignos podem se apresentar com características diversas, resultado da combinação de vários fatores como conteúdo (sólido, misto ou líquido), ecogenicidade (isoecóico, hipoecóico ou hiperecóico), halo hipoecóico periférico (presente ou ausente), calcificações (presentes ou ausentes), contornos (regulares ou irregulares), número de nódulos e parênquima tireoidiano adjacente.

\section{CARACTERÍSTICAS ULTRA-SONOGRÁFICAS}

\section{Ecogenicidade}

O tecido tireoidiano é caracterizado ultra-sonograficamente pela proporção de células e colóide. Em uma glândula normal, grande parte das ondas sonoras emitidas pelo transdutor atinge a interface entre células e colóide em ângulo reto e são refletidas de volta ao equipamento, sem dispersão; conseqüentemente, a imagem ultra-sonográfica resultante será brilhante e terá ecogenicidade considerada normal. Para tecidos macrofoliculares, as ondas sonoras atingirão uma maior interface entre células e colóide, em ângulo reto, portanto uma maior quantidade de ondas sonoras será refletida de volta ao equipamento e a imagem resultante apresentará ecogenicidade aumentada ou hiperecóica (figura 1A). Em tecidos microfoliculares, como na neoplasia micro- folicular, somente uma pequena parcela das ondas sonoras atinge a interface em ângulo reto. Assim, somente uma parte das ondas sonoras retorna ao transdutor, originando uma imagem com baixa ecogenicidade ou hipoecóica (escura) (figura 1B).

Tecidos tireoidianos sem folículos, como a variante fibrosa da tireoidite de Hashimoto e o tumor sólido ou trabecular, não apresentam interface entre células e colóide. Conseqüentemente, esses tecidos são hipoecóicos. Septos de fibrose são vistos como uma linha ecogênica atravessando o parênquima glandular. Folículos dilatados com conteúdo colóide aparecem como pequenas estruturas arredondadas anecóicas (escuras). Os pequenos cistos também aparecem como imagens anecóicas arredondadas, podendo apresentar imagens hiperecóicas em seu interior, que correspondem ao colóide denso (figura $1 \mathrm{C}$ ).

Portanto, a ecogenicidade do tecido tireoidiano pode ser considerada como uma medida da quantidade de colóide ou da quantidade de células. Como os tumores malignos geralmente são estruturas microfoliculares, sólidas ou trabeculares (hipoecóicas), uma lesão nodular hipoecóica apresenta maior probabilidade de malignidade, quando comparado a uma lesão isoecóica ou hiperecóica. No entanto, a baixa ecogenicidade não é suficientemente específica. Isso significa apenas que a quantidade de células está aumentada e que o conteúdo colóide está diminuído, em comparação ao tecido tireoidiano normal. O diagnóstico histológico, nesses casos, pode ser tanto benigno como maligno (7).

A baixa ecogenicidade isolada é uma característica ultra-sonográfica importante, com valor preditivo positivo de $50 \%$ a $63 \%$ (8). Os nódulos sólidos isoecóicos, que representam $3 \%$ a $25 \%$ dos nódulos, são malignos em $7 \%$ a $25 \%$ dos casos. Já os nódulos sólidos hiperecóicos, que representam $20 \%$ das lesões nodulares, são malignos em $1,3 \%$ a $4 \%$ dos casos. Os carcinomas bem diferenciados totalmente sólidos são hipoecóicos em $55 \%$ a $95 \%$ dos casos (8).

\section{Calcificações}

As calcificações aparecem como imagens acentuadamente hiperecóicas ou ecorrefringentes, com sombra acústica posterior, e podem estar presentes no bócio colóide adenomatoso e nas neoplasias benignas e malignas da tireóide. Os depósitos de cálcio são encontrados em diferentes tipos histológicos de câncer da tireóide, como o papilífero, medular e o carcinoma anaplásico (figura $1 \mathrm{D}$ ).

As microcalcificações encontradas no carcinoma papilífero representam os corpos psamomatosos, que são formados pela calcificação de trombos intravascu- 

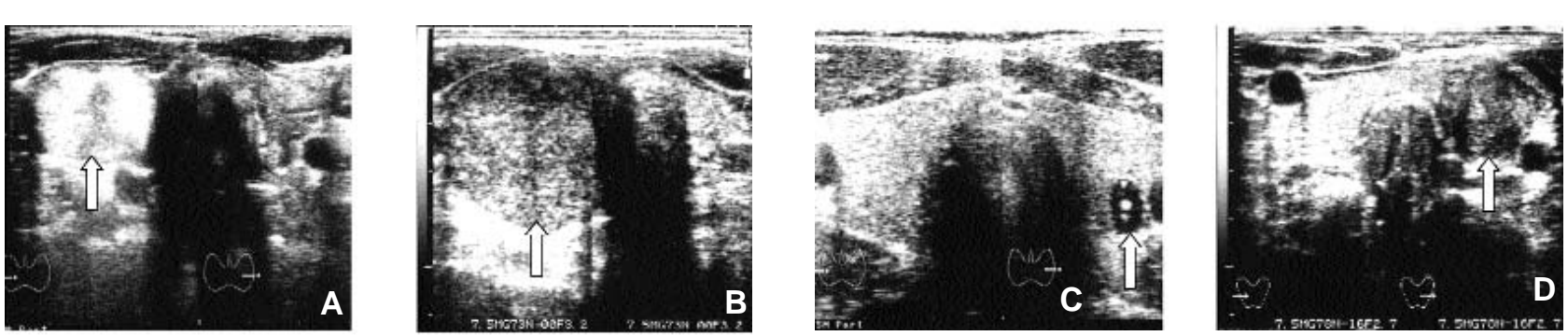

Figura 1. A. Corte transversal do lobo direito. Nódulo hiperecóico (seta). B. Corte transversal do lobo direito. Nódulo hipoecóico (seta). C. Corte transversal do lobo esquerdo. Cisto (seta). D. Corte transversal do lobo esquerdo. Nódulo com microcalcificações (seta).

lares intratumorais ou de extremidades infartadas das papilas malignas $(9)$.

Para se avaliar o significado das calcificações detectadas à ultra-sonografia, foi realizado um estudo que encontrou uma forte associação entre calcificações intranodulares e malignidade, principalmente em pacientes jovens ou em nódulos únicos. Nesta série, as calcificações foram encontradas em $54 \%$ dos pacientes com câncer da tireóide e em $\mathbf{5 2} \%$ dos carcinomas papilíferos (10). Em outro estudo, analisando algumas características ultra-sonográficas das lesões nodulares, tais como ecogenicidade, conteúdo, contornos e grau de vascularização interna, não foi encontrada diferença significativa entre os nódulos benignos e malignos. Entretanto, havia um aumento no risco de malignidade, estatisticamente significativo, quando se identificavam microcalcificações no interior dos nódulos (11).

Takashima e cols. demonstraram que a presença de microcalcificações no interior dos nódulos era a única característica ultra-sonográfica que poderia predizer malignidade (12). Este sinal teve acurácia de 76\%, especificidade de $93 \%$ e valor preditivo positivo de $70 \%$, mas com uma sensibilidade de apenas 36\%. Das várias combinações entre microcalcificações e um dos outros achados ultra-sonográficos, a combinação entre microcalcificações e nódulo de textura sólida mostrou a acurácia mais alta, de $77 \%$, especificidade de $96 \%$ e valor preditivo positivo de $75 \%$, porém a sua sensibilidade foi de apenas 30\%. Esses resultados sugerem que, em casos de discrepância entre o diagnóstico ultra-sonográfico e o citológico, todos os outros dados clínicos devem ser considerados e uma nova biópsia para confirmação pode ser também considerada (12).

\section{Halo hipoecogênico}

A presença do halo hipoecóico ao redor do nódulo tem sido considerada como um sinal de benignidade. Embora a maioria dos trabalhos relacione essa característica com a cápsula do nódulo, não se sabe ao certo o seu significado histológico. Para investigar o significado do halo hipoecóico periférico, foi realizado um estudo onde 28 nódulos foram analisados pela ultra-sonografia e correlacionados com o exame anátomo-patológico. Todos os dezoito nódulos sem halo periférico eram benignos. De 10 nódulos com halo, dois eram malignos e 8 benignos. A análise histológica também não chegou a uma conclusão definitiva a respeito da natureza do halo. Foi levantada apenas a hipótese do halo hipoecóico corresponder a uma região inflamatória peri-nodular (13). Em outro estudo, foi demonstrado que a ausência do halo hipoecóico periférico foi o sinal isolado com maior valor preditivo para malignidade, com uma sensibilidade de 66,6\% e especificidade de 77,0\% (14). Em nossa experiência, conseguimos identificar halo hipoecóico apenas nos nódulos isoecóicos ou hiperecóicos, isto é, aqueles que apresentam ecogenicidade sugestiva de benignidade. Já nos nódulos acentuadamente hipoecóicos, que apresentam maior risco de malignidade, geralmente não identificamos o halo, mesmo que ele esteja presente, pois a ecogenicidade do halo é semelhante à do nódulo.

\section{Ecoestrutura}

Os nódulos tireóideos podem ser divididos ecoestruturalmente em 5 categorias: cisto, misto (predominantemente sólido ou líquido), sólido hiperecóico, sólido isoecóico e sólido hipoecóico.

O cisto significa exatamente um espaço preenchido por líquido coberto por células epiteliais, que muitas vezes parece originar-se de uma dilatação anormal de túbulos, ductos ou cavidades pré-existentes. Entretanto, alterações inflamatórias, ou outras, podem fazer com que um cisto verdadeiro perca a sua camada celular de revestimento e torne-se envolvido por tecido de granulação ou fibrose. A camada de células epiteliais envolvendo o cisto geralmente não é neoplásica e este raramente é maligno. Eles representam aproximadamente $1 \%$ a $3 \%$ de todas as lesões nodulares e são benignos em $98 \%$ dos casos. Entretanto, uma imagem cística anecóica, com uma massa sólida em sua parede, contendo múltiplos pontos 

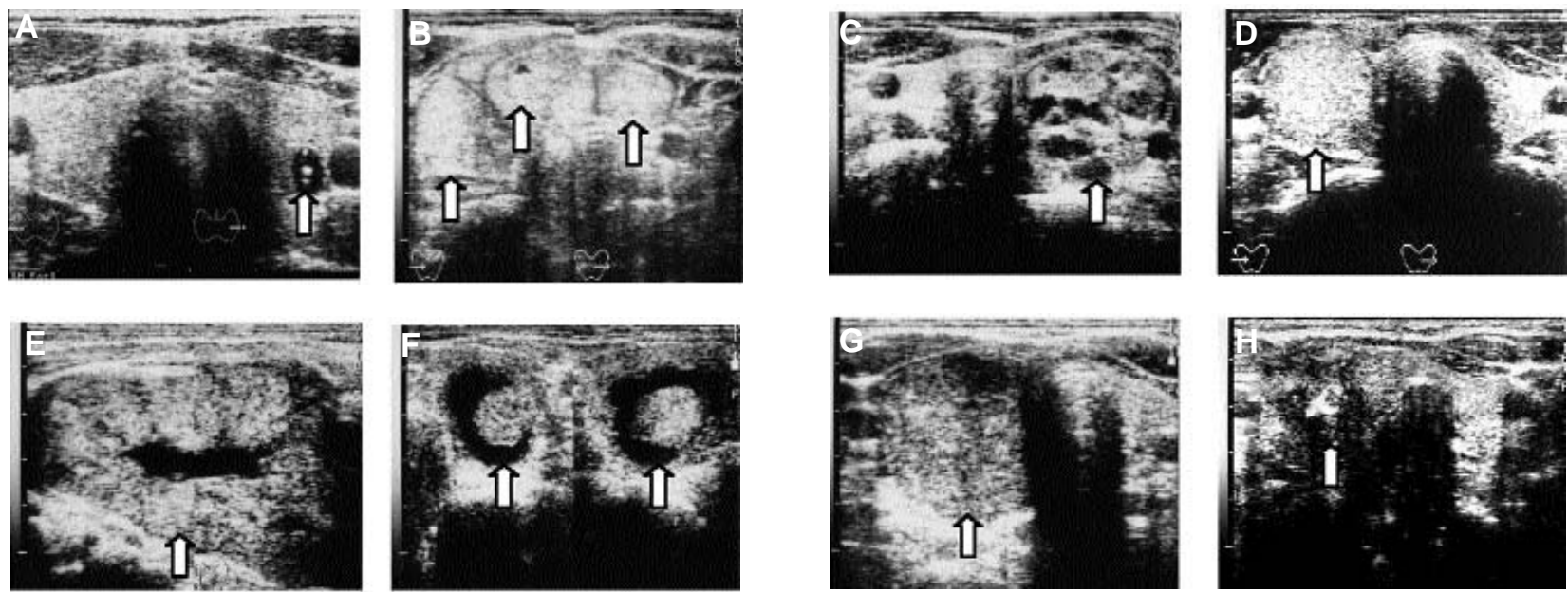

Figura 2. Classificação ultra-sonográfica dos nódulos tireóideos.

A. Grau I. Imagem anecóica de contornos lisos e regulares. B. Grau II. Nódulo sólido hiper ou isoecóico em uma glândula de textura heterogênea ou multinodular. C. Grau II. Nódulo misto tipo "esponja". D. Grau III. Nódulo sólido único, hiper ou isoecóico em uma glândula de textura homogênea. E. Grau III. Nódulo sólido com área líquida central. F. Grau III. Cisto com tumoração parietal. G. Grau III. Nódulo sólido hipoecóico. H. Grau IV. Nódulo sólido hipoecóico, de contornos irregulares e com microcalcificações.

hiperecogênicos, sugerindo microcalcificações, pode estar associada ao carcinoma papilífero, requerendo sempre uma avaliação cuidadosa ou mesmo um tratamento cirúrgico $(15,16)$ (figura $2 \mathrm{~F}$ ).

Por outro lado, as neoplasias sólidas podem apresentar necrose isquêmica, com conteúdo líquido preenchendo a lacuna provocada pela necrose do tecido tumoral, processo denominado de degeneração cística, que deve ser diferenciado de um cisto verdadeiro (figura 2E). Segundo Leenhardt, os nódulos com conteúdo líquido representam $25 \%$ das lesões nodulares e são malignos em $10 \%$ a $20 \%$ dos casos (8). Muitos autores, entretanto, têm considerado todas as lesões contendo líquido, independentemente de eles serem cistos simples da tireóide ou nódulos sólidos com degeneração cística, como cistos. Portanto, a literatura de cistos tireóideos é imprecisa (17).

Os nódulos mistos apresentam múltiplas áreas líquidas dispersas pelo parênquima, dando um aspecto semelhante a uma esponja, e são classificados como predominantemente sólidos ou líquidos, quando a proporção de sólido ou líquido é maior que 50\%, respectivamente.

Os nódulos sólidos benignos geralmente são isoecóicos ou hiperecóicos, com contornos regulares, freqüientemente com halo hipoecóico periférico completo e uniforme. Já os carcinomas papilíferos da tireóide geralmente são hipoecogênicos, com contornos irregulares, sem halo hipoecóico e com microcalcificações.

\section{NÓDULOS BENIGNOS E MALIGNOS AO EXAME ULTRA-SONOGRÁFICO}

Os achados ultra-sonográficos tornam-se preditivos para malignidade somente quando múltiplos sinais ou características malignas estão simultaneamente presentes em um nódulo tireóideo. No estudo realizado por Raggo e cols., a ausência de halo com presença de microcalcificações foi a combinação mais importante no diagnóstico das lesões malignas da tireóide, com uma sensibilidade de $26,6 \%$ e especificidade de $93,2 \%$ (14).

Mais recentemente, Shimura e cols., analisando 10 características ultra-sonográficas, mostraram que somente o formato, os contornos e a ecogenicidade foram importantes na diferenciação entre os carcinomas papilíferos e os nódulos benignos da tireóide (18).

\section{ULTRA-SONOGRAFIA X CITOLOGIA}

Watters e cols. compararam a acurácia da ultra-sonografia e da citologia na avaliação de 120 pacientes portadores de nódulos tireoidianos submetidos a tireoidectomia. Os resultados para o diagnóstico de malignidade obtidos pelo exame ultra-sonográfico foram semelhantes aos da citologia, com sensibilidade de $74 \%$ versus $86 \%$, especificidade de $83 \%$ versus $85 \%$, valor preditivo positivo de $51 \%$ versus $58 \%$, valor preditivo negativo de $93 \%$ versus $96 \%$ e acurácia de $82 \%$ 
versus $84 \%$. No entanto, para o diagnóstico de bócio colóide adenomatoso, os resultados obtidos com a ultra-sonografia foram muito superiores aos da PAAF, com sensibilidade de $70 \%$ versus $55 \%$, especificidade de $93 \%$ versus $86 \%$, valor preditivo positivo de $92 \%$ versus $83 \%$, valor preditivo negativo de $73 \%$ versus $61 \%$ e acurácia de $81 \%$ versus $69 \%$. Portanto, esse estudo sugere que as duas modalidades diagnósticas são complementares e a associação das duas melhora sensivelmente o diagnóstico dos nódulos tireóideos (19).

\section{CLASSIFICAÇÃO ULTRA-SONOGRÁFICA DOS NÓDULOS TIREÓIDEOS}

Para conhecer a probabilidade de malignidade de qualquer lesão nodular da tireóide, propusemos uma classificação ultra-sonográfica dos nódulos tireóideos de acordo com o seu risco de malignidade. Essa classificação foi baseada nas seguintes características:

Conteúdo: a) Cisto com conteúdo totalmente líquido, b) cisto com um tumor sólido em sua parede, c) nódulo inteiramente sólido, d) nódulo sólido com uma área líquida central, e) nódulo misto ou complexo (com áreas líquidas dispersas em um nódulo sólido).

Ecogenicidade: a) Isoecóico: nódulo sólido com amplitude de ecos igual ao do parênquima tireoidiano normal, b) hipoecóico: nódulo sólido com amplitude de ecos menor do que o parênquima tireoidiano normal, c) hiperecóico: nódulo sólido com amplitude de ecos maior que o parênquima tireoidiano normal.

Contornos: a) regulares ou b) irregulares.

Microcalcificações: Pequenos pontos hiperecogênicos, alguns com sombra acústica posterior, presentes no interior dos nódulos sólidos.

Além disso, analisamos o parênquima tireoidiano adjacente ao nódulo, que pode se apresentar com textura homogênea e sem outras imagens nodulares, ou com textura heterogênea e com outras imagens nodulares sólidas, nódulos mistos ou cistos. Baseado nestas características, os nódulos foram agrupados em quatro grupos, correspondentes, progressivamente, à maior probabilidade de malignidade da lesão (figura 2):
Grau I (benigno): Imagem anecóica arredondada, de paredes lisas e de conteúdo líquido.

Grau II (benigno): Nódulo misto, predominantemente sólido ou líquido; nódulo sólido isoecóico ou hiperecóico com ou sem calcificações grosseiras (densas), com ou sem componente líquido e com o restante do parênquima de textura heterogênea, podendo se identificar outras imagens nodulares sólidas, mistas ou cistos.

Grau III (indeterminado): Nódulo sólido isoecóico ou hiperecóico, único; nódulo sólido hipoecóico; nódulo sólido com uma área líquida central; cisto com um tumor parietal.

Grau IV (suspeito para malignidade): Nódulo sólido hipoecóico, de contornos irregulares e com microcalcificações em seu interior.

\section{DIAGNÓSTICO ULTRA-SONOGRÁFICO DOS NÓDULOS TIREÓIDEOS}

Em nossa experiência de 2.468 pacientes portadores de nódulos tireoidianos submetidos ao exame ultrasonográfico e punção aspirativa guiada pela ultra-sonografia, 1.039 tiveram nódulos classificados ultra-sonograficamente como grau I ou II (benignos), 1.276 como grau III (indeterminado) e 153 como grau IV (suspeito para malignidade).

Ao compararmos os resultados da classificação ultra-sonográfica e o diagnóstico citológico (tabela 1 ), observamos que, dos 1.039 nódulos classificados como benignos (graus I ou II ao exame ultra-sonográfico), $902(86,8 \%)$ também apresentaram citologia benigna, $96(9,2 \%)$ apresentaram citologia indeterminada, $37(3,6 \%)$ apresentaram citologia suspeita e apenas $4(0,4 \%)$ apresentaram citologia maligna. Dos 1.276 pacientes portadores de nódulos indeterminados ao exame ultra-sonográfico (grau III), 743 $(58,2 \%)$ apresentaram citologia benigna, 272 $(21,33 \%)$ indeterminada, $176(13,8 \%)$ suspeita e 85 $(6,7 \%)$ maligna. Cento e cinqüenta e três pacientes apresentaram nódulos suspeitos para malignidade ao exame ultra-sonográfico (grau IV), sendo que 88

Tabela 1. Classificação ultra-sonográfica dos nódulos tireóideos: comparação com exame citológico.

\begin{tabular}{lccccc}
\hline $\begin{array}{l}\text { Classificação } \\
\text { Ultra-sonografia }\end{array}$ & $\begin{array}{c}\text { Benigno } \\
\mathbf{n}(\%)\end{array}$ & $\begin{array}{c}\text { Exame Citológico } \\
\text { Inderminado } \\
\mathbf{n}(\%)\end{array}$ & $\begin{array}{c}\text { Suspeito } \\
\mathbf{n}(\%)\end{array}$ & $\begin{array}{c}\text { Maligno } \\
\mathbf{n}(\%)\end{array}$ & $\begin{array}{c}\text { Total } \\
\mathbf{n}(\%)\end{array}$ \\
Graus I e II & $902(86,8)$ & $96(9,2)$ & $37(3,6)$ & $4(0,4)$ & $1039(100)$ \\
Grau II & $743(58,2)$ & $272(21,3)$ & $176(13,8)$ & $85(6,7)$ & $1276(100)$ \\
Grau IV & $38(24,8)$ & $7(4,6)$ & $20(13,1)$ & $88(57,5)$ & $153(100)$ \\
Total & $1683(68,2)$ & $375(15,2)$ & $233(9,4)$ & $177(7,2)$ & $2468(100)$ \\
\hline
\end{tabular}


Tabela 2. Classificação ultra-sonográfica e câncer.

\begin{tabular}{cccc}
\hline & Grau & Câncer (-) & Câncer (+) \\
& I $(n=2)$ & $2(100,00 \%)$ & $0(0,00 \%)$ \\
& II $(n=56)$ & $54(96,43 \%)$ & $2(3,57 \%)$ \\
& III $(n=146)$ & $73(50,00 \%)$ & $73(50,00 \%)$ \\
Total & IV $(n=71)$ & $4(5,63 \%)$ & $67(94,37 \%)$ \\
\hline & 275 & $133(48,36 \%)$ & $142(51,64 \%)$
\end{tabular}

Tabela 3. Relação entre a classificação ultra-sonográfica e câncer.

\begin{tabular}{lccc}
\hline Ultra-sonografia & \multicolumn{2}{c}{ Câncer } & Total \\
& Não & Sim & \\
I-II & $56(96,55 \%)$ & $2(3,45 \%)$ & 58 \\
III-IV & $77(35,48 \%)$ & $140(64,52 \%)$ & 217 \\
Total & $133(48,36 \%)$ & $142(51,64 \%)$ & 275 \\
\hline
\end{tabular}

Sensibilidade: $98,6 \%$, Especificidade: $42,1 \%$, Valor preditivo positivo: $64,5 \%$, Valor preditivo negativo: $96,6 \%$, Acurácia: $71,3 \%$, odds ratio: 50,9 , IC: $95 \%(12,09-314,35)$.

(57,5\%) também apresentaram citologia maligna, 20 $(13,1 \%)$ suspeita para malignidade, $7(4,6 \%)$ indeterminada e $38(24,8 \%)$ benigna. Do total de pacientes biopsiados, 68,2\% apresentaram citologia benigna, $15,2 \%$ citologia indeterminada, $9,4 \%$ suspeita e $7,2 \%$ maligna. Os pacientes com material insuficiente ou inadequado para análise citológica foram excluídos do estudo, já que não foi possível realizar o exame citológico.

Ao compararmos os resultados do exame ultrasonográfico com o exame anátomo-patológico de 275 pacientes operados, observamos que 56/58 (96,6\%) pacientes que apresentaram lesões benignas à ultrasonografia (graus I e II) também tiveram exame anátomo-patológico benigno. Cento e quarenta e seis pacientes apresentaram nódulos indeterminados (grau III) ao ultra-som, sendo $73(50 \%)$ benignos e 73 (50\%) malignos ao exame histológico. Dos 71 pacientes com nódulos suspeitos para malignidade (grau IV), 67 (94,37\%) eram malignos e $4(5,63 \%)$ benignos ao exame anátomo-patológico. Realizado o teste diagnóstico, a classificação ultra-sonográfica grau II apresentou sensibilidade de $100,00 \%$ e especificidade de 1,50\%; o grau III, sensibilidade de $98,59 \%$ e especificidade de $42,11 \%$; e o grau IV, sensibilidade de $47,18 \%$ e especificidade de $96,99 \%$ (tabela 2 ).

Para efeito de análise estatística, os nódulos classificados ultra-sonograficamente como graus I e II foram considerados benignos e os nódulos classificados como graus III e IV como malignos (tabela 3 ). Desta forma, de 58 pacientes portadores de nódulos classificados como benignos, $56(96,55 \%)$ tiveram confirmação histológica de lesões benignas e 2
$(3,45 \%)$, de lesões malignas. De 217 pacientes com nódulos considerados malignos ao exame ultra-sonográfico, $77(35,48 \%)$ tiveram diagnóstico anátomopatológico benigno e $140(64,52 \%)$, maligno. A sensibilidade do método foi de $98,59 \%$, especificidade de $42,11 \%$, acurácia de $71,27 \%$ e odds ratio de $50,9 \mathrm{com}$ IC de 95\% (12,09-314,35) (tabela 3$)$.

Concluímos que existe uma concordância entre os resultados da classificação ultra-sonográfica e citológica dos nódulos benignos. Do total de 2.468 nódulos analisados, $42 \%$ foram considerados benignos (graus I ou II) ao exame ultra-sonográfico. Devido ao seu alto valor preditivo negativo (VPN=96,6\%), esses nódulos podem ser acompanhados clinicamente, sem a necessidade de serem biopsiados. Por outro lado, os nódulos classificados como indeterminados ou suspeitos ao exame ultra-sonográfico devem ser biopsiados (20). Do total de 142 pacientes portadores de câncer da tireóide, somente $47,2 \%$ foram considerados indeterminados ou suspeitos ao exame ultra-sonográfico, reforçando a necessidade de avaliarmos o risco de malignidade de todos os nódulos tireoidianos.

\section{DOPPLER EM TIREÓIDE}

O Doppler colorido possibilita a caracterização do padrão de vascularização dos nódulos tireóideos. As variações de freqüência da onda sonora emitida pelas hemácias em movimento são demonstradas em escala de cores, sendo que as tonalidades mais claras indicam velocidades mais altas e tons mais escuros indicam velocidades mais baixas.

$\mathrm{O}$ padrão de vascularização pode ser avaliado através de 3 maneiras:

1) Análise qualitativa através do mapeamento com Doppler colorido ou com Doppler de amplitude, 2 ) análise quantitativa através do cálculo da velocidade do pico sistólico, e 3) análise semi-quantitativa através dos índices de resistência e pulsatilidade.

O Doppler colorido baseia-se no fato de que a proliferação celular está relacionada a um aumento da sua vascularização. Nódulos com fluxo predominantemente periférico apresentam maior probabilidade de benignidade e nódulos com fluxo predominantemente central apresentam maior probabilidade de malignidade.

Papini e cols. demonstraram, em 2002, que as lesões malignas apresentam maior vascularização intranodular central que os nódulos benignos $(74,2 \% \mathrm{x}$ $19,1 \%$ ), com uma sensibilidade de $74,2 \%$, especificidade de $80,8 \%$ e valor preditivo positivo de 24,0 (21). 
Outros autores também demonstraram a importância do Doppler no diagnóstico das lesões malignas da tireóide $(22,23)$.

Em 2003, Frates e cols. demonstraram que o risco de malignidade é maior nos nódulos sólidos e hipervascularizados. Entretanto, o estudo também demonstrou que as características do Doppler não podem excluir malignidade porque $14 \%$ dos nódulos que apresentavam ausência de vascularização eram malignos (24). Da mesma forma, outros autores também não conseguiram demonstrar uma melhora na acurácia diagnóstica com o uso do Doppler colorido (25-28).

No estudo realizado por Chammas e cols., em 2005 , foi demonstrada uma associação positiva entre o padrão de fluxo vascular e os resultados citológicos. Foi demonstrado também maior índice de resistência vascular nos nódulos malignos (29). No mesmo ano, De Nicola e cols., analisando o padrão de fluxo e o índice de resistência vascular nos nódulos com citologia indeterminada para neoplasia folicular, encontraram uma associação positiva entre fluxo sanguíneo predominantemente periférico e doença nodular benigna. Entretanto, essa análise do padrão do fluxo sanguíneo não pode excluir malignidade porque $20 \%$ dos nódulos malignos apresentaram fluxo predominantemente periférico. $\mathrm{O}$ índice de resistência vascular encontrado nos nódulos, utilizando-se um corte de 0,75 para o diagnóstico de malignidade, apresentou uma acurácia de $91 \%$, especificidade de $97 \%$, valor preditivo negativo de $92 \%$, porém uma sensibilidade de apenas $40 \%$ e um valor preditivo positivo de $67 \%$ (30).

Em um artigo publicado neste ano, Tamsel e cols. também realizaram um estudo para determinar se o padrão de fluxo vascular ou a análise espectral, incluindo o índice de resistência e a velocidade sistólica máxima, podem ser utilizados para diferenciar um nódulo maligno de um benigno. Nesse trabalho, os nódulos malignos apresentaram um índice de resistência de 0,60 nos vasos intranodulares e 0,58 nos vasos perinodulares. Os valores não foram significativamente diferentes dos encontrados nos nódulos benignos, que apresentaram índice de resistência de 0,57 nos vasos intranodulares e 0,56 nos vasos perinodulares. $\mathrm{O}$ trabalho concluiu que as características do Doppler, incluindo o padrão de fluxo vascular, índice de resistência e a velocidade sistólica máxima não são parâmetros úteis para diferenciar os nódulos malignos dos benignos. Portanto, estas características do Doppler não podem ser utilizadas como métodos diagnósticos para determinar quais nódulos devem ser submetidos à biópsia (31).

Em 2004, os ultra-sonografistas da Sociedade Americana de Radiologia reuniram um grupo formado por radiologistas, endocrinologistas, citopatologistas e cirurgiões para discutir a conduta diante dos nódulos tireoidianos diagnosticados pela ultra-sonografia. Quanto ao uso do Doppler colorido no diagnóstico dos nódulos malignos, as opiniões também não foram unânimes. Alguns estudos demonstraram a importância do Doppler colorido na avaliação do nódulo tireóideo, porém outros não demonstraram um aumento na acurácia no diagnóstico das lesões nodulares malignas da tireóide. O grupo de especialistas concluiu que, assim como outras características ultrasonográficas de malignidade, o Doppler colorido não pode diagnosticar ou excluir malignidade com alto grau de confiança. O fluxo sanguíneo interno ou central somente indica uma maior probabilidade de malignidade da lesão nodular. O consenso concluiu, também, que não é necessário o uso do Doppler colorido para seleção de nódulos para biópsia.

Em nossa experiência, temos observado que os nódulos autônomos e adenomas foliculares freqüentemente apresentam vascularização central, enquanto vários nódulos que apresentaram citologia positiva para carcinoma papilífero apresentaram-se sem vascularização ou pouco vascularizados (dados não publicados). Portanto, em nossa opinião, consideramos o aumento de vascularização central e da resistência vascular, apenas mais duas características ultra-sonográficas que, juntamente com a hipoecogenicidade e presença de calcificações, tornam o nódulo mais suspeito para malignidade neoplasia. No entanto, a ausência de vascularização central não exclui malignidade (32).

\section{SEGUIMENTO ULTRA-SONOGRÁFICO DO CÂNCER DE TIREÓIDE}

Metástases para linfonodos regionais estão presentes em 20 a $90 \%$ dos pacientes com carcinoma papilífero ao diagnóstico e em menor proporção nos carcinomas foliculares. A variante folicular do carcinoma papilífero também está associada a uma incidência menor de metástases ganglionares que o padrão papilífero clássico (40).

A importância do envolvimento dos gânglios cervicais, como fator prognóstico do carcinoma bem diferenciado da tireóide, ainda é controversa. Alguns estudos mostraram que a presença e o número de gânglios cervicais acometidos por metástases de carcinoma bem diferenciado da tireóide aparentemente não altera o prognóstico da doença (33-35).

Entretanto, em um trabalho realizado em Pisa, onde foram avaliados 191 pacientes com carcinoma papilífero da tireóide com metástases ganglionares, 32 
tinham doença persistente, 8 tinham metástases a distância e 6 morreram da doença após um seguimento médio de 5,8 anos, mostrando uma alta taxa de mortalidade (36).

A dosagem de tireoglobulina juntamente com o exame ultra-sonográfico cervical apresenta alta sensibilidade para diagnóstico de metástases ganglionares. Concentrações de tireoglobulina acima de $2,3 \mathrm{ng} / \mathrm{ml}$, em pacientes submetidos à tireoidectomia total por carcinoma bem diferenciado da tireóide, sem reposição hormonal com levotiroxina durante 3 semanas após a cirurgia, demonstrou presença de tecido tireoidiano remanescente e/ou risco de metástases cervicais ou a distância (37). Portanto, é recomendável que esses pacientes sejam avaliados cuidadosamente, com dosagens de tireoglobulina sérica seriada para verificar o comportamento dos níveis de $\mathrm{Tg}$, se está havendo queda, manutenção ou aumento, e exames de imagens para detectar possíveis metástases cervicais ou a distância.

\section{AVALIAÇÃO ULTRA-SONOGRÁFICA PRÉ-OPERATÓRIA DE PACIENTES COM METÁSTASES GANGLIONARES DE CARCINOMA DA TIREÓIDE}

A presença de metástases ganglionares cervicais é um achado freqüente no carcinoma papilífero da tireóide, atingindo mais de $30 \%$ dos pacientes, sendo que o envolvimento ganglionar pode ocorrer mesmo nos microcarcinomas papilíferos. O exame ultra-sonográfico pode detectar gânglios metastáticos ou recidivas tumorais em tecidos próximos ao leito tireoidiano em 39\% dos pacientes que não apresentam alterações ao exame físico. Estes achados pré-operatórios podem alterar o procedimento cirúrgico, facilitar a completa ressecção do tumor e diminuir o índice de recorrência loco-regional (38).

A presença de metástases ganglionares no préoperatório indica maior probabilidade de recidiva ganglionar após o tratamento (39).

\section{CARACTERÍSTICAS ULTRA-SONOGRÁFICAS DOS LINFONODOS CERVICAIS}

No seguimento de pacientes com carcinoma bem diferenciado da tireóide, é importante diferenciar um gânglio cervical inflamatório de um tumoral. Quando a ultra-sonografia cervical é realizada com um transdutor de alta freqüência, é possível analisar alguns detalhes dos gânglios cervicais que podem indicar a natureza benigna ou maligna da lesão.
Os gânglios normais são geralmente hipoecóicos, alongados, finos e com uma faixa ecogênica central que caracteriza o hilo vascular.

Um dos indicadores para saber diferenciar um gânglio inflamatório ou reacional de um metastático é a medida do diâmetro longitudinal/anteroposterior. Quando a razão for maior que 1,5, geralmente os gânglios são de natureza inflamatória. Os gânglios cujos índicessão menores que 1,5 apresentam maior probabilidade de serem de natureza tumoral. Portanto, gânglios arredondados possuem uma probabilidade maior de malignidade, quando comparados aos gânglios alongados e finos. Além disso, os gânglios malignos geralmente são homogêneos, hiperecóicos em relação ao músculo esternocleidomastóideo e podem apresentar microcalcificações $(41,42)$.

Os gânglios metastáticos dos carcinomas papilíferos da tireóide podem apresentar conteúdo cístico em 70\% dos casos. Esse padrão é quase que exclusivamente encontrado nas metástases ganglionares dos carcinomas papilíferos da tireóide (43).

\section{PAAF GUIADA PELA ULTRA-SONOGRAFIA NA AVALIAÇÃO DOS GÂNGLIOS CERVICAIS}

A PAAF guiada pela ultra-sonografia é o método mais sensível para avaliação de um gânglio cervical suspeito. Sempre que houver algum conteúdo líquido em um gânglio cervical, a PAAF deverá ser guiada pela ultrasonografia para atingir a área sólida com maior probabilidade de apresentar material satisfatório para análise (44).

O exame ultra-sonográfico bem realizado é capaz de detectar metástases ganglionares não identificadas ao exame físico ou mesmo quando a PCI é negativa e a tireoglobulina, indetectável (45-47).

\section{DOSAGEM DA TIREOGLOBULINA NO LAVADO DA AGULHA DA PUNÇÃO}

Após a punção do gânglio, uma parte do esfregaço é utilizada para o exame citológico. A agulha com o restante do material é lavada com $1 \mathrm{ml}$ de soro fisiológico e o lavado é utilizado para dosagem de Tg. Nas metástases ganglionares, os níveis de Tg no lavado estão muito acima do nível sérico.

A dosagem de $\mathrm{Tg}$ no lavado da agulha de punção de linfonodo cervical tem se mostrado mais sensível que a citologia no diagnóstico de metástase cervical, principalmente quando existe conteúdo líquido (48) e não é afetada pela presença de auto-anticorpos anti-Tg circulantes $(49,50)$. 


\section{SUMÁRIO E CONCLUSÃO}

As características ultra-sonográficas dos nódulos tireóideos permitem classificá-los em benignos, indeterminados e suspeitos para malignidade. Os nódulos classificados como benignos (graus I e II) apresentam correlação positiva com o exame citológico em 96,6\% dos casos. Os nódulos classificados como indeterminados (grau III) apresentam citologia indeterminada em 21,3\% dos casos, suspeita para malignidade em $13,8 \%$ e maligna em $6,7 \%$. Já os nódulos suspeitos para malignidade ao exame ultra-sonográfico apresentam citologia maligna em $57,5 \%$, suspeita em $13,1 \%$ e indeterminada em $4,6 \%$. Portanto, nódulos com características ultra-sonográficas benignas podem ser acompanhados clinicamente sem necessidade de serem biopsiados. Por outro lado, nódulos indeterminados ou suspeitos à ultra-sonografia apresentam um maior risco de malignidade e devem ser submetidos à punção aspirativa por agulha fina.

A análise qualitativa através do mapeamento com o Doppler colorido mostra que os nódulos malignos apresentam maior vascularização intranodular central que os nódulos benignos. No entanto, uma parcela não desprezível de nódulos malignos se apresenta sem vascularização central ou pouco vascularizados. Portanto, a presença de vascularização central associada a um aumento da resistência vascular é uma característica que, juntamente com outros aspectos ultra-sonográficos como hipoecogenicidade e presença de microcalcificações, tornam o nódulo mais suspeito para malignidade. No entanto, nódulos que apresentam ausência de vascularização central não podem ser considerados benignos.

O exame ultra-sonográfico bem realizado é o método mais sensível para detectar metástases ganglionares cervicais. A punção aspirativa guiada pela ultra-sonografia dos linfonodos suspeitos e a dosagem de tireoglobulina no lavado da punção tem-se mostrado mais sensível que a citologia isolada no diagnóstico de metástase cervical do carcinoma bem diferenciado de tireóide.

\section{REFERÊNCIAS}

1. Van Herle AJ, Rich P, Ljung BME, Aschcraft MW, Solmar DH, Keeller EB. The thyroid nodule. Ann Intern Med 1982;(96):221-32.

2. Rojeski MT, Gharib HN. Nodular thyroid disease. Evaluation and management. Engl J Med 1985;313:428-36.

3. Brander A, Viikinoski P, Nickels J, Kivisaari L. Thyroid gland: US screening in middle-age women with no previous thyroid disease. Radiology 1989;173:507-10.

4. Horlocken TT, Hay ID, James EM, Reading CC, Charboneau JW. Prevalence of incidental nodular thyroid disease detected during high resolution parathyroid ultrasonography. In: Medeiros-Neto G, Gaitan E (eds). Frontiers of Thyroidology. New York: Plenum Press, 1986. pp. 1309-12.
5. Cooper DS, Doherty GM, Haugen BR, Kloos RT, Lee SL, Mandel SJ, et al. Management guidelines for patients with thyroid nodules and differentiated thyroid cancer: The American Thyroid Association guidelines taskforce. Thyroid 2006;16(2):109-42.

6. Jun P, Chow LC, Jeffrey RB. The sonographic features of papillary thyroid carcinomas: pictorial essay. Ultrasound $\mathbf{Q}$ 2005;21(1):39-45.

7. Müller HW, Schroder S, Schneider C, Seifert G. Sonographic tissue characterisation in thyroid gland diagnosis. A correlation between sonography and histology. Klin Wochenschr 1985;63:706-10.

8. Leenhardt L, Tramalloni J, Aurengo H, Delbot T, Guillausseau C, Aurengo A. Echographie des nodules thyroïdiens: I'échographiste face aux exigences du clinicien [Echography of thyroid nodules: the echographist's response to the clinician]. La Presse Médicale 1994;23(30):1389-92.

9. Johannessen JV, Sobrinho-Simões M. The origin and significance of thyroid psammoma bodies. Lab Invest 1980; 43(3):287-96.

10. Kakkos SK, Scopa CD, Chalmoukis AK, Karachalios DA, Spiloitis JD, Harkoftakis JG, et al. Relative risk of cancer in sonographically detected thyroid nodules with calcifications. J Clin Ultrasound 2000;28(7):347-52.

11. Iannuccilli JD, Cronan JJ, Monchik JM. Risk for malignancy of thyroid nodules as assessed by sonographic criteria: the need for biopsy. J Ultrasound Med 2004;23(11):1455-64.

12. Takashima S, Fukuda H, Nomura N, Kishimoto H, Kim T, Kobayashi T. Thyroid nodules: re-evaluation with ultrasound. J Clin Ultrasound 1995;23(3):179-84.

13. Propper RA, Skolnick ML, Weinstein BJ, Dekker A. The nonspecificity of the thyroid halo sign. $J$ Clin Ultrasound 1980;8:129-32.

14. Rago T, Vitti $P$, Chiovato L, Mazzeo S, De Liperi A, Miccoli P, et al. Role of conventional ultrasonography and color flowdoppler sonography in predicting malignancy in 'cold' thyroid nodules. Eur J Endocrinol 1998;138:41-6.

15. Gimondo P, Mirk P, Messina G, Pizzi G, Tomei A. Il ruolo delI'ecografia nella patologia tiroidea. Minerva Med 1993;84:671-80.

16. Hatabu H, Kasagi K, Yamamoto K, lida Y, Misaki T, Hidaka A, et al. Cystic papillary carcinoma of the thyroid gland: a new sonographic sign. Clin Radiol 1991;43:121-4.

17. De Los Santos ET, Keyhani-Rofagha SK, Cunningham JJ, Mazzaferri EL. Cystic thyroid nodules: the dilemma of malignant lesions. Arch Intern Med 1990;150:1422-7.

18. Shimura $H$, Haraguchi $K$, Hiejima $Y$, Fukunari N, Fujimoto $Y$, Katagiri $M$, et al. Distinct diagnostic criteria for ultrasonographic examination of papillary thyroid carcinoma: a muticenter study. Thyroid 2005;15(3):251-8.

19. Watters DA, Ahuja AT, Evans RM, Chick W, King WW, Metreweli C, et al. Role of ultrasound in the management of thyroid nodules. Am J Surg 1992;164:654-7.

20. Tomimori EK, Bisi H, Medeiros-Neto G, Camargo RYA. Avaliação ultra-sonográfica dos nódulos tireóideos: comparação com exame citológico e histopatológico. Arq Bras Endocrinol Metab 2004;48:105-13.

21. Papini E, Guglielmi R, Bianchini A, Crescenzi A, Taccogna S, Nardi $F$, et al. Risk of malignancy in nonpalpable thyroid nodules: predictive value of ultrasound and color Doppler features. J Clin Endocrinol Metab 2002;87:1941-6.

22. Chan BK, Desser TS, McDougall IR, Weigel RJ, Jeffrey RB. Common and uncommon sonographic features of papillary thyroid carcinoma. J Ultrasound Med 2003;22:1083-90.

23. Pacella CM, Guglielmi R, Fabbrini R, Bianchini A, Rinaldi R, Panunzi C, et al. Papillary carcinoma in small hypoechoic thyroid nodules: predictive value of echo color Doppler evaluation - preliminary results. J Exp Clin Cancer Res 1998; 17:127-8.

24. Frates MC, Benson CB, Doubilet PM, Cibas ES, Marqusee E. Can color Doppler sonography aid in the prediction of malignancy of thyroid nodules? J Ultrasound Med 2003; 22(2):127-31. 
25. Wienke JR, Chong WK, Fielding JR, Zou KH, Mittelstaedt CA. Sonographic features of benign thyroid nodules: interobserver reliability and overlap with malignancy. J Ultrasound Med 2003;22:1027-31.

26. Iannuccilli JD, Cronan JJ, Monchik JM. Risk for malignancy of thyroid nodules as assessed by sonographic criteria. $\mathbf{J}$ Ultrasound Med 2004;23:1455-64.

27. Rago T, Vitti P, Chiovato L, Mazzeo S, De Liperi A, Miccoli P, et al. Role of conventional ultrasonography and color flowDoppler sonography in predicting malignancy in 'cold' thyroid nodules. Eur J Endocrinol 1998;138:41-6.

28. Shimamoto K, Endo T, Ishigaki T, Sakuma S, Makino N. Thyroid nodules: evaluation with color Doppler ultrasonography. J Ultrasound Med 1993;12:673-8.

29. Chammas MC, Gerhard R, de Oliveira IR, Widman A, de Barros $N$, Durazzo $M$, et al. Thyroid nodules: evaluation with power Doppler and duplex Doppler ultrasound. Otolaryngol Head Neck Surgery 2005;132(6):874-82.

30. De Nicola H, Szejnfeld J, Logullo AF, Wolosker AM, Souza LR, Chiferi V Jr. Flow pattern and vascular resistive index as predictors of malignancy risk in thyroid follicular neoplasms. $\mathbf{J}$ Ultrasound 2005;24(7):897-904.

31. Tamsel S, Demirpolat G, Erdogan M, Nart D, Karadeniz M, Uluer $\mathrm{H}$, et al. Power Doppler US patterns of vascularity and spectral Doppler US parameters in predicting malignancy in thyroid nodules. Clin Radiol 2007:62(3):245-51.

32. Frates MC, Benson CB, Charboneau JW, Cibas ES, Clark $\mathrm{OH}_{\text {, }}$ Coleman BG, et al. Management of thyroid nodules detected at US: Society of Radiologists in Ultrasound consensus conference statement. Radiology 2005;237(3):794-800.

33. Sato N, Oyamatsu M, Koyama Y, Emura I, Tamiya Y, Hatakeyama K. Do the level of nodal disease according to the TNM classification and the number of involved cervical nodes reflect prognosis in patients with differentiated carcinoma of the thyroid gland? J Surg Oncol 1998;69(3):151-5.

34. Hay ID. Papillary thyroid carcinoma. Endocrinol Metab Clin N Am 1990;19:545-76.

35. Hay ID, Bergstralh EJ, Goellner JR, Ebersold JR, Grant CS. Predicting outcome in papillary thyroid carcinoma: development of a reliable prognostic scoring system in a cohort of 1779 patients surgically treated at one instituition during 1940 through 1989. Surgery 1993;14:1050-8.

36. Pacini F, Cetani F, Miccoli $P$, Mancusi F, Ceccarelli $C$, Lippi F, et al. Outcome of 309 patients with metastatic differentiated thyroid carcinoma treated with radioiodine. Word J Surg 1994; $18: 600-4$

37. Lima N, Cavaliere H, Tomimori E, Knobel M, Medeiros-Neto $\mathrm{G}$. Prognostic value of serial serum thyroglobulin determinations after total thyroidectomy for differentiated thyroid cancer. J Endocrinol Invest 2002;25(2):110-5.

38. Kouvaraki MA, Shapiro SE, Fornage BD, Edeiken-Monro BS, Sherman SI, Vassilopoulou-Sellin R, et al. Role of preoperative ultrasonography in the surgical management of patients with thyroid cancer. Surgery 2003;134(6):946-54

39. Ito Y, Tomoda C, Uruno T, Takamura Y, Miya A, Kobayashi K, et al. Preoperative Ultrasonographic examination for lymph node metastasis: usefulness when designing lymph node dissection for papillary microcarcinoma of the thyroid. World $\mathbf{J}$ Surg 2004;28(5):498-501.
40. Jain M, Khan A, Patwardhan N, Reale F, Safran M. Follicular variant of papillary thyroid carcinoma: a comparative study of histopathologic features and cytology results in 141 patients. Endocr Pract 2001;7(2):79-84.

41. Giuffrida D, Santonocito MG, lurato MP, Freni V, Ippolito A Squatrito S. Echography at "high resolution" in the diagnosis of cervical lymphadenopathies in follow-up of thyroid carcinoma. Minerva Endocrinol 1997;22(3):61-6.

42. Ahuja AT, Chow L, Chick W, King W, Metreweli C. Metastatic cervical nodes in papillary carcinoma of the thyroid: ultrasound and histological correlation. Clin Radiol 1995;50(4):229-31.

43. Kessler A, Rappaport Y, Blank A, Marmor S, Weiss J, Graif M. Cystic appearance of cervical lymph nodes is characteristic of metastatic papillary thyroid carcinoma. J Clin Ultrasound 2003:31(1):21-5.

44. Tseng FY, Hsiao YL, Chang TC. Cytologic features of metastatic papillary thyroid carcinoma in cervical lymph nodes. Acta Cytol 2002;46(6):1043-8.

45. Frilling A, Gorges R, Tecklenborg K, Gassmann P, Bockhorn $M$, Clausen $M$, et al. Value of preoperative diagnostic modalities in patients with recurrent thyroid carcinoma. Surgery 2000;128(6):1067-74.

46. Antonelli A, Miccoli P, Fallahi P, Grosso M, Nesti C, Spinelli C, et al. Role of neck ultrasonography in the follow-up of children operated on for thyroid papillary cancer. Thyroid 2003;13(5):479-84.

47. Torlontano M, Crocetti U, D'Aloiso L, Bonfitto N, Di Giorgio A, Modoni S, et al. Serum thyroglobulin and 131| whole body scan after recombinant human TSH stimulation in the followup of low-risk patients with differentiated thyroid cancer. Eur J Endocrinol 2003;148(1):19-24.

48. Cignarelli M, Ambrosi A, Marino A, Lamacchia O, Campo M, Picca $G$, et al. Diagnostic utility of thyroglobulin detection in fine-needle aspiration of cervical cystic metastatic lymph nodes from papillary thyroid cancer with negative cytology. Thyroid 2003;13(12):1163-7.

49. Boi F, Baghino G, Atszeni F, Lai ML, Fas G, Mariotti S. The diagnostic value for differentiated thyroid carcinoma metastases of thyroglobulin measurement in washout fluid from fine-needle aspiration biopsy of neck lymph nodes is maintained in the presence of circulating anti-Tg antibodies. $\mathbf{J}$ Clin Endocrinol Metab 2006;91(14):1364-9.

50. Baskin HJ. Detection of recurrent papillary thyroid carcinoma by thyroglobulin assessment in the needle washout after fine-needle aspiration of suspicious lymph nodes. Thyroid 2004;14(11):959-63.

Endereço para correspondência:

Rosalinda Yossie Asato de Camargo

Rua Prof. Artur Ramos 241, conj. 63

01554-011 São Paulo, SP

E-mail: ryasato@uol.com.br 